\title{
EDITORIAL
}

\section{PRINCIPIOS, DIÁLOGO Y CONTRAPUNTO}

Nos encontramos a cuatro meses de las elecciones presidenciales y parlamentarias de este año en Chile y, como todo año eleccionario, este se encuentra marcado por debates, confrontaciones de ideas y, por supuesto, una profusa propuesta legislativa en todos aquellos temas en que grupos, partidos y candidatos quieren remarcar una posición, interés o preocupación.

Es lógico que así sea y el público jurídico ha de entender el ánimo que infunde esta cantidad de propuestas, a veces presentadas con más apuro que minuciosidad, pero siempre en referencia a temas que nos preocupan o inquietan a todos, en los que notamos que falta legislación adecuada o en los que incluso podemos identificar más la carencia de una conceptualización rigurosa que la necesidad de una normativa adicional o modificatoria de la ya existente. Es cuestión de opiniones y, precisamente, la posibilidad de opinar y de expresar pareceres diversos sobre múltiples materias es el tema que ocupa el editorial de esta oportunidad.

El mundo jurídico no dista en realidad del mundo social en dos aspectos: primero, en que en ambos el diálogo es una herramienta indispensable para la comprensión, el unir fuerzas y alcanzar metas, aun entre personas y corrientes diferentes en cierto modo contrapuestas; segundo, en que los principios y las ideas propias no se empañan ni se renuncian al confrontarlas con pensamientos de otro signo, en la medida que el escenario sea de respeto y trato digno y no uno de descalificación, mofa o liviandad. Nuestra verdad no es menos verdad si la exponemos a la mirada y al escrutinio de quienes sostienen una interpretación diferente.

En esa perspectiva, a una revista jurídica científica, como la nuestra, que a la vez tiene la particularidad de ser un importante medio de comunicación de la Facultad a la que pertenece, siendo a su vez esta última parte integral de una universidad católica y pontificia, le asiste el deber de mostrar el estado del arte en lo que al Derecho se refiere, sea en sus tendencias normativas, jurisprudenciales o, por supuesto, doctrinarias, al mismo tiempo que cumple con el estricto deber de comunicar la visión que sobre esas materias tiene la entidad que la ha creado y el pensamiento que la Iglesia ha transmitido durante muchísimos años acerca de temas tan relevantes como la dignidad del ser humano y el valor de la vida.

La coincidencia de tales tareas podría visualizarse como una traba al actuar del editor, como un sesgo en su tarea o una aparente contradicción, lo cual, a nuestro juicio, constituiría una lectura incorrecta de la Revista Chilena de Derecho.

La presentación de las diversas posturas existentes en nuestra realidad nacional sobre proyectos de ley, resolución de casos concretos o formas de abordar problemáticas factuales, en secciones como lo es Contrapunto -específicamente dedicada a la contingencia jurídica-, corresponde al cumplimiento de nuestro deber de informar al lector, de proporcionarle herramientas para facilitar su conocimiento y, por supuesto, de brindarle 
los insumos necesarios para su búsqueda de la verdad, aun sobre la base del examen de opiniones de quienes no comparten nuestra visión en materias de alto contenido valórico: "Es cierto que, si se observa atentamente, incluso en la reflexión filosófica de aquellos que han contribuido a aumentar la distancia entre fe y razón aparecen a veces gérmenes preciosos de pensamiento que, profundizados y desarrollados con rectitud de mente y corazón, pueden ayudar a descubrir el camino de la verdad. Estos gérmenes de pensamiento se encuentran, por ejemplo, en los análisis profundos sobre la percepción y la experiencia, lo imaginario y el inconsciente, la personalidad y la intersubjetividad, la libertad y los valores, el tiempo y la historia; incluso el tema de la muerte puede llegar a ser para todo pensador una seria llamada a buscar dentro de sí mismo el sentido auténtico de la propia existencia" (Fides et Ratio).

Nuestra adscripción a un método científico de tratamiento de la cuestión jurídica, nuestro interés en el trabajo de aquellas personas que reflexionan sobre el Derecho desde la excelencia académica y la libertad de investigación y la apertura de nuestras páginas a la colaboración noble y desinteresada de aquellos que emplean su tiempo en la reflexión sobre lo que es bueno, lo que es justo y lo que es posible, desde diversas experiencias y sensibilidades, no nos aparta del camino trazado desde nuestra fundación, sino que es el reflejo de la voluntad de diálogo magisterial ("El deseo de que este diálogo sea conducido solo por el amor a la verdad, guardando siempre la debida prudencia, no excluye por nuestra parte a nadie", Concilio Vaticano II) y de la valoración de la ciencia como una forma de servicio a la verdad y a la persona humana ("La libertad de investigación y de enseñanza es reconocida y respetada según los principios y métodos propios de cada disciplina, siempre que sean salvaguardados los derechos de las personas y de la comunidad y dentro de las exigencias de la verdad y del bien común”, Ex corde Ecclesiae).

En tiempos de opiniones, de debates, pero también de unidad y de interés legítimo por nuestra sociedad y nuestra Patria, vaya pues nuestro aporte de tinta y de papel, que también lo es de espíritu y de corazón. 